\title{
Erratum to: Branch duct IPMTs: value of cross-sectional imaging in the assessment of biological behavior and follow-up
}

G. Carbognin, ${ }^{1}$ G. Zamboni, ${ }^{1}$ L. Pinali, ${ }^{1}$ E. Dalla Chiara, ${ }^{1}$ V. Girardi, ${ }^{2}$ R. Salvia, ${ }^{1}$ R. Pozzi Mucelli ${ }^{1}$

${ }^{1}$ Department of Radiology, University Hospital “G. B. Rossi”, P. le LA Scuro, 10, 37134 Verona, Italy

${ }^{2}$ Department of Surgery, University Hospital “G. B. Rossi,”, P. le LA Scuro, 10, 37134 Verona, Italy

Erratum to: Abdom Imaging (2006) 31:320-325

DOI 10.1007/s00261-004-0127-1

This article was inadvertently published a second time under DOI: 10.1007/s00261-006-9132-x.

Official publication is under DOI: 10.1007/s00261-004-0127-1 in Abdom Imaging (2006) 31:320-325.

The online version of the original article can be found under doi:10.1007/s00261-004-0127-1.

Correspondence to: G. Carbognin; email: giovanni.carbognin@, azosp.vr.it 